University of Wollongong

Research Online

Faculty of Social Sciences - Papers (Archive) Faculty of Arts, Social Sciences \& Humanities

2020

Participation in domains of physical activity among australian youth during the transition from childhood to adolescence: A longitudinal study

Byron Kemp

University of Wollongong, bjk687@uowmail.edu.au

Anne-Maree Parrish

University of Wollongong, aparrish@uow.edu.au

Marijka Batterham

University of Wollongong, marijka@uow.edu.au

Dylan P. Cliff

University of Wollongong, dylanc@uow.edu.au

Follow this and additional works at: https://ro.uow.edu.au/sspapers

Part of the Education Commons, and the Social and Behavioral Sciences Commons

Research Online is the open access institutional repository for the University of Wollongong. For further information contact the UOW Library: research-pubs@uow.edu.au 


\title{
Participation in domains of physical activity among australian youth during the transition from childhood to adolescence: A longitudinal study
}

\author{
Abstract \\ Background: Information about the domains of physical activity (PA) that are most prone to decline \\ between late childhood (11 y), early adolescence ( $13 \mathrm{y})$, and mid-adolescence (15y) may support more \\ targeted health promotion strategies. This study explored longitudinal trends in nonorganized PA, \\ organized PA, active transport and active chores/work between childhood and adolescence, and potential \\ sociodemographic moderators of changes. Methods: Data were sourced from the Longitudinal Study of \\ Australian Children $(n=4108)$. Participation in PA domains was extracted from youth time-use diaries. \\ Potential moderators were sex, Indigenous status, language spoken at home, socioeconomic position, \\ and geographical remoteness. Results: A large quadratic decline in nonorganized PA $(-48 \mathrm{~min} / \mathrm{d}, \mathrm{P}<.001)$ \\ was moderated by sex $(\beta=5.55, P=.047)$ and home language $(\beta=8.55, P=.047)$, with girls $(-39 \mathrm{~min} / \mathrm{d})$ \\ and those from a non-English speaking background $(-46 \mathrm{~min} / \mathrm{d})$ declining more between 11 and 13 years. \\ Active chores/work increased between 11 and 13 years $(+4 \mathrm{~min} / \mathrm{d}, \mathrm{P}<.001)$ and then stabilized. Active \\ transport increased among boys between 11 and 13 years $(+6 \mathrm{~min} / \mathrm{d}, \mathrm{P}<.001)$ and then declined \\ between 13 and 15 years $(-4 \mathrm{~min} / \mathrm{d}, \mathrm{P}<.001)$. Organized PA remained stable. Conclusions: The \\ longitudinal decline in PA participation may be lessened by targeting nonorganized PA between childhood \\ and adolescence. Future interventions may target girls or those from non-English speaking backgrounds \\ during this transition.

\section{Disciplines} \\ Education | Social and Behavioral Sciences

\section{Publication Details} \\ Kemp, B., Parrish, A., Batterham, M. \& Cliff, D. (2020). Participation in domains of physical activity among \\ australian youth during the transition from childhood to adolescence: A longitudinal study. Journal of \\ Physical Activity and Health, 17 (3), 278-286.
}


1 Title: Participation in domains of physical activity among Australian youth during the transition from

2 childhood to adolescence: a longitudinal study

3 Journal: Journal of Physical Activity and Health

\section{Authors:}

$5 \quad$ Mr. Byron J. Kemp (bjk687@uowmail.edu.au)

$6 \quad$ Dr. Anne-Maree Parrish (aparrish@uow.edu.au)

$7 \quad$ Prof. Marijka Batterham (marijka@uow.edu.au)

$8 \quad$ Dr. Dylan P. Cliff (dylanc@uow.edu.au) 


\section{Abstract}

10 Background: Information about the domains of physical activity (PA) that are most prone to decline between late childhood (11y), early adolescence (13y) and mid-adolescence (15y) may support more targeted health promotion strategies. This study explored longitudinal trends in non-organized PA, organized PA, active transport and active chores/work between childhood and adolescence; and

14 potential sociodemographic moderators of changes.

15 Methods: Data were sourced from the Longitudinal Study of Australian Children $(n=4,108)$.

16 Participation in PA domains was extracted from youth time-use diaries. Potential moderators were

17 sex, Indigenous status, language spoken at home, socioeconomic position and geographical remoteness.

Results: A large quadratic decline in non-organized PA $(-48 \mathrm{~min} / \mathrm{d}, \mathrm{p}<0.001)$ was moderated by sex $(\beta=5.55, \mathrm{p}=0.047)$ and home language $(\beta=8.55, \mathrm{p}=0.047)$, with girls $(-39 \mathrm{~min} / \mathrm{d})$ and those from a non-English speaking background ( $-46 \mathrm{~min} / \mathrm{d})$ declining more between $11-13 \mathrm{y}$. Active chores/work increased between 11-13y $(+4 \mathrm{~min} / \mathrm{d}, \mathrm{p}<0.001)$ and then stabilized. Active transport increased among boys between 11-13y $(+6 \mathrm{~min} / \mathrm{d}, \mathrm{p}<0.001)$ and then declined between $13 \mathrm{y}-15 \mathrm{y}(-4 \mathrm{~min} / \mathrm{d}, \mathrm{p}<0.001)$. Organized PA remained stable.

Conclusions: The longitudinal decline in PA participation may be lessened by targeting nonorganized PA between childhood and adolescence. Future interventions may target girls or those from non-English speaking backgrounds during this transition.

Keywords: Exercise; sport; health behavior; adolescent; public health 
30

Regular physical activity (PA) is associated with many health benefits for children and youth. ${ }^{1}$ However, global analyses suggest that youth across a range of countries are generally not meeting PA recommendations. ${ }^{2,3}$ In Australia, only $19 \%$ of 5-17 year olds engage in at least 60 minutes of moderate- to vigorous intensity physical activity (MVPA) every day, with 5-8 year olds being the most likely to meet this guideline $(36 \%)$ and $15-17$ year olds being the least likely $(6 \%) .{ }^{4}$ This is consistent with age-related declines in PA participation reported elsewhere. ${ }^{5}$ There is also some evidence that PA participation during childhood and adolescence may track into adulthood, which highlights the importance of PA promotion strategies among youth. ${ }^{6}$

An emerging area of research interest relates to domains of PA, such as transportation, household/occupational and leisure-time PA. ${ }^{7}$ Transportation PA is also known as active transport, which includes activities such as walking or cycling to school or work. ${ }^{8}$ Household/occupational PA is also known as active chores/work and this includes activities such as raking leaves and digging. ${ }^{9,10}$ Among children and adolescents, leisure-time PA is sometimes divided into two sub-categories: (1) organized PA (activities with rules and structure that are usually led by an adult, e.g. club sports or dance classes) ${ }^{11}$ and non-organized PA (more freely chosen, unstructured and intrinsically motivated activities, e.g. playground games and kicking a ball in the park). ${ }^{8}$ Information about participation in domains of PA can provide a more nuanced understanding of PA behavior that may not be captured in studies of more general outcomes such as moderate-to-vigorous intensity physical activity (MVPA). ${ }^{12}$ Although studies of overall PA are helpful in understanding whether youth are sufficiently active, longitudinal studies of PA domains may provide more specific behavioral targets for intervention.

Despite this, the longitudinal changes in domains of PA during childhood and adolescence are still not well understood. In particular, a recent systematic review of longitudinal changes in PA domains during childhood and adolescence found that none of the included studies had investigated more than two domains of PA in the same sample. ${ }^{13}$ The concurrent examination of multiple domains of PA is particularly useful for identifying the domains that may contribute most to overall PA change. 
55 Furthermore, national cross-sectional evidence in Australia indicates that non-organized PA may be

56 linked to the overall decline in PA in youth. ${ }^{4}$ However, the recent systematic review included only

57 three longitudinal studies of non-organized PA internationally, ${ }^{14-16}$ and the overall synthesis of these

58 studies in the transition from childhood to adolescence was inconclusive. ${ }^{13}$

59 In addition to targeting specific domains of PA, interventions may also deliver targeted strategies to 60 particular segments of youth based on socio-demographic characteristics ${ }^{17}$. Due to the relationship 61 between PA participation and health, ${ }^{1}$ the social determinants of health provide one framework for 62 identifying broad characteristics for segmentation. ${ }^{18}$ In Australia, key areas of mortality inequity have been summarized in terms of five socio-demographic characteristics: sex, socioeconomic status, country of birth, Indigenous status and remoteness. ${ }^{19}$ Therefore, an exploration by these sociodemographic characteristics may highlight priority segments of the population for targeting.

The present study aimed to investigate two research questions: (1) How does the duration of overall PA, non-organized PA, organized PA, active transport and active chores/work change between late childhood (10-11 years), early adolescence (12-13 years) and mid-adolescence (14-15 years)?; and (2) Are these changes moderated by sex, socioeconomic position, language spoken at home, Indigenous status or geographical remoteness? Based on national cross-sectional statistics, ${ }^{4}$ we hypothesized that non-organized PA would decline the most out of all domains. We also hypothesized that changes in overall PA and at least one domain of PA would be moderated by at least one of the five sociodemographic characteristics tested.

\section{Method}

\section{Setting and procedures}

This study used data from the Kindergarten (K) cohort of the Longitudinal Study of Australian Children (LSAC), a research project managed by the Australian Department of Social Services (DSS) ${ }^{20}$ This cohort comprises a nationally-representative sample of Australian children who were recruited at age 4 to 5 years in 2004 and followed-up every two years to date. LSAC data collection procedures were approved by the Australian Institute of Family Studies Ethics Committee, and 
81 participants provided informed consent. ${ }^{21}$ The use of data in the present study has been approved by

82 the University of Wollongong Human Research Ethics Committee (HE 2017/275).

83

84

\section{Participants}

Participants were recruited from the Australian Medicare database via a two-stage clustered design (random selection of postcodes then families). Eligible children were born between March 1999 and February $2000 .{ }^{20}$ At baseline, 4,983 families were recruited (50.4\% of those invited to participate).$^{20}$ The present study uses LSAC data collected during Wave 4 (2010), Wave 5 (2012) and Wave 6 (2014). On average, participants were aged 11 years, 13 years and 15 years at these time-points.

\section{Physical activity measures}

Data relating to participation in domains of PA were extracted from time-use diary (TUD) instruments completed by participants at 11 years, 13 years and 15 years of age. This is the longest available timeseries in which compatible measurements of all four PA domains were collected via the LSAC TUD because reduced 'light diaries' were used prior to Wave $4 .{ }^{22}$ Participants recorded their activities in their own words over a 24-hour period on the day before their interview. ${ }^{22}$ Participants who attended school on this day were asked to record activities conducted during school breaks but not during lessons (such as physical education (PE) lessons). Interviewers then recorded diary entries based on a predetermined coding framework during the home visit. ${ }^{22}$ Interviewers were trained to prompt participants for additional information during this process (e.g. to fill gaps in the diary). ${ }^{22}$

In the present study, the duration of each PA domain was calculated from one or more TUD activity codes. The duration of each activity in the dataset was firstly calculated as the difference between the start and end time. It was assumed that each activity ended at the start time of the next activity in sequence for each child, with the final activity ending at the child's bed time. The total duration of each activity code was then aggregated for each participant. Although participants could record up to six activities concurrently, some domains (such as organized PA) seemed incongruent as a concurrent activity. For consistency, participation in domains of PA was based on the primary activity selected at a time. A full concordance of PA domains and activity codes is provided in Supplementary File 1. 
Some changes were evident in the coding framework across waves, mostly due to disaggregation in later waves. For example, organized PA and non-organized PA were divided into specific sports and activities in wave 6 (15 years). It is not expected that this would have altered the response pattern of participants because activities were still recorded in participants' own words via an open-ended paper diary, irrespective of the coding framework. Furthermore, activity codes such as 'unstructured active play - other' were included in wave 6 to ensure that entire domains of PA could still be constructed.

The activity codes comprising active chores/work also expanded in later waves to reflect ageappropriate developments (e.g. employment-type activities such as 'labourers and related workers' were introduced but rarely used in wave 6). Activity codes were included in active chores and work if they were deemed likely to exceed 3.0 metabolic equivalents (METs) according to the most recent compendium of energy expenditures for youth. ${ }^{23}$ The threshold of 3.0 METs was chosen as the minimum cut-off for MVPA in accordance with World Health Organization guidelines. ${ }^{24}$ If a suitable match could not be found in the current youth compendium, a determination was based on (in order): (1) the previous youth compendium ${ }^{25}$; (2) the current adult compendium ${ }^{26}$; or (3) author consensus.

\section{Other measures}

The main explanatory variable in this study was the wave of measurement (w4/w5/w6). Potential moderators were sex, Indigenous status (yes/no), whether the child spoke a language other than English (LOTE) at home (yes/no), socioeconomic position (SEP) and geographical remoteness (major city/regional-remote). SEP is a composite indicator of annual family income, parents' educational attainment and parents' occupations (z-scored), calculated and provided by LSAC. ${ }^{27}$ Geographical remoteness was based on the Australian Statistical Geography Standard Remoteness Structure. ${ }^{28}$

Potential confounding variables were season of measurement and whether the child attended school on the day of TUD completion (yes/no). The season was derived from the date of interview. School attendance was included as a variable in the LSAC datasets. Where data were missing for this variable, imputation was completed based on data reported about "school lessons" in the TUD.

\section{Analysis}



statistical analyses were performed using Stata 13 (StataCorp, College Station, TX, USA). Effects were considered to be statistically significant at $\mathrm{p}<0.05$.

Frequency histograms revealed that many respondents naturally rounded their TUD entries to the nearest 5 minutes. Therefore the duration of each domain of PA was consistently rounded to nearest 5 minutes for all cases. Population data weights were applied to improve the representativeness of the data and to reduce bias associated with attrition. The LSAC Wave 1 and 4 longitudinal population weight was chosen because it preserved the maximum number of cases.

Longitudinal changes in each domain of PA were tested in separate multilevel mixed-effects models.

142 Changes in overall PA were also tested (an aggregate of the aforementioned domains). Multilevel modelling does not require complete cases for every time-point, ${ }^{29}$ thus all available data were used. Preliminary models tested the effect of wave on each PA outcome (level 1), nested within individuals (level 2). Models were then adjusted for potential confounding effects (season of measurement and whether the child attended school on the day of TUD completion). A higher-order quadratic term was also included in models $\left(\right.$ wave $\left.^{2}\right)$. Statistically significant quadratic effects were given precedence over statistically significant linear effects. Post-hoc models tested interactions between wave and each potential moderator. Interactions were tested one-by-one for each PA outcome, resulting in 25 posthoc models (5 potential moderators * 5 PA outcomes). Interaction models were not adjusted for multiple hypothesis testing. The average annual rate of change in overall PA was calculated to enable comparison with a recent meta-analysis of PA change during adolescence ${ }^{5}$. As data were collected biennially, the percentage change between waves was assumed to occur evenly across specific years of age. The percentage change between each year was then calculated and averaged.

\section{Results}

A total of 4,108 participants were included in the study. Of these participants, 3,691 (90\%) provided complete data for at least two waves and 2,782 (68\%) provided complete data for all three waves. As shown in Table 1, the sex distribution of participants was relatively consistent in all waves, and the 
age intervals between waves were equal. Few participants were Aboriginal or Torres Strait Islanders $(\leq 3.0 \%)$, although this reflects the Australian population $(2.8 \%$ in 2016$) .{ }^{30}$ Interviews rarely occurred during Summer $(\leq 3.5 \%)$ because LSAC data collection usually runs from Autumn to Spring. ${ }^{20}$

[Insert Table 1 approximately here]

\section{Overall physical activity}

Table 2 shows longitudinal trends in overall PA participation and by domain. On average, overall PA participation declined by 45 minutes/day between 11 and 15 years of age (-10.9\% per year). The adjusted model for overall PA revealed a statistically significant quadratic time effect $(\beta=7.65,95 \%$ $\mathrm{CI}=3.80,11.51 ; \mathrm{p}<0.001)$, with the sharpest decline between 11 and 13 years. As shown in Table 3, this quadratic time effect was moderated by sex $(\beta=11.74,95 \% \mathrm{CI}=4.07,19.41 ; \mathrm{p}=0.003)$ and LOTE $(\beta=17.47,95 \% \mathrm{CI}=4.79,30.16 ; \mathrm{p}=0.007)$. The decline in girls' participation mostly occurred between 11 and 13 years, whereas the decline in boys' participation was spread more evenly between waves. Among those who spoke languages other than English at home, overall PA participation declined sharply between 11 and 13 years but the change between 13 and 15 years was not statistically significant. By contrast, the trend among those who spoke English at home was more similar to that of the total sample. No other statistically significant moderators of overall PA were identified. Figure 1 illustrates the longitudinal trends in overall PA and the domains of PA.

[Insert Table 2 approximately here]

[Insert Table 3 approximately here]

[Insert Figure 1 approximately here]

\section{Organized PA}

Organized PA was the most stable domain in the present study. There was no statistically significant change between 11 and 15 years of age (see Table 2).

\section{Non-organized PA}


The largest decline in the present study occurred in non-organized PA. Average non-organized PA

184 participation declined by 48 minutes/day between 11 and 15 years (see Table 2). The adjusted model

185 for non-organized PA revealed a statistically significant quadratic time effect $(\beta=12.66,95 \%$

$186 \mathrm{CI}=9.92,15.39 ; \mathrm{p}<0.001$ ) which was similar to the decline in overall PA (see Figure 1). Non-

187 organized PA declined sharply between 11 and 13 years and then weakened somewhat between 13

188 and 15 years. The decline in non-organized PA was moderated by sex and LOTE (see Table 3). The

189 decline was sharper between 11 and 13 years among girls and between 13 and 15 years among boys.

190 Among those who spoke languages other than English at home, non-organized PA declined sharply

191 between 11 and 13 years but the change between 13 and 15 years was not statistically significant. The

192 trend among those who spoke English at home was similar to that of the total sample.

\section{Active transport}

194

195

196

197

In general, the change in active transport between 11 and 15 years was not statistically significant (see Table 2). However, the adjusted mixed model for this domain revealed a statistically significant quadratic time effect $(\beta=-2.96,95 \% \mathrm{CI}=-4.37,-1.55 ; \mathrm{p}<0.001)$, with an increase between 11 and 13 years and an almost equal decline between 13 and 15 years. Sex was a statistically significant moderator of this quadratic trend $(\beta=4.40,95 \% \mathrm{CI}=1.61,7.18 ; \mathrm{p}=0.002)$ (see Table 3 ). Participation among both sexes peaked at 13 years, although the trend was only statistically significant among boys. No other statistically significant moderators of active transport were evident.

\section{Active chores and work}

Active chores/work was the only domain with a statistically significant increase in participation between 11 and 15 years ( $+4 \mathrm{~min} /$ day) (see Table 2$)$. A statistically significant quadratic time effect was observed $(\beta=-2.66,95 \% \mathrm{CI}=-4.32,-0.99 ; \mathrm{p}=0.002)$, with an increase between 11 and 13 years that levelled off between 13 and 15 years. No statistically significant moderators of active chores/work were evident. Supplementary File 2 provides the results of all moderation tests.

\section{Discussion}


This study aimed to investigate longitudinal trends in overall PA, non-organized PA, organized PA, active transport and active chores/work between late childhood (11 years) and mid-adolescence (15 years); and to assess potential sociodemographic moderators of changes. Overall PA participation declined by 45 minutes/day between 11 and 15 years of age (-10.9\% per year). Distinct patterns were observed in each domain of PA. Organized PA was the most stable, with no statistically significant changes between 11 and 15 years of age. Non-organized PA declined the most of all domains ( -48 min/day) and this was moderated by sex and LOTE. Among boys, there was a statistically significant increase in active transport between 11 and 13 years of age, followed by a statistically significant decline between 13 and 15 years of age. A similar trend was observed among girls, although this was not statistically significant. Finally, there was a statistically significant increase in active chores/work between 11 and 13 years of age but no change between 13 and 15 years of age.

The decline in overall PA in the present study (-10.9\% per year) was above average compared with a meta-analysis of PA change during adolescence $(-7.0 \%$ per year $),{ }^{5}$ although this was still within the 95\% confidence interval based on studies of PA duration. ${ }^{5}$ The differences in overall PA by language spoken at home are also consistent with an Australian cross-sectional study, which suggested that academic, family and cultural responsibilities may assume greater importance than PA in some nonEnglish speaking households. ${ }^{11}$ The differences in changes in overall PA by sex are also consistent with evidence that PA may be more prone to decline among girls during early adolescence and boys during later adolescence. ${ }^{5}$ Girls may be more prone to drop out of PA in early adolescence due to selfconsciousness during puberty, ${ }^{31}$ whereas this is not a common barrier among adolescent boys. ${ }^{32}$

The large decline in non-organized PA in the present study is consistent with national cross-sectional data in Australia. ${ }^{4}$ These statistics reveal a statistically significant difference in non-organized MVPA among those aged 12-14 years, compared with those aged 9-11 years $(-20 \mathrm{~min} / \mathrm{day} ; \mathrm{p}<0.05)$, and this was similar to the difference in overall MVPA (-19 min/day; $p<0.05) .{ }^{4}$ Qualitative data suggest that this decline in non-organized PA may be related to changing social norms during the transition to adolescence. ${ }^{33,34}$ For example, it has been reported that participants who withdraw from PA during adolescence often note the development of a more competitive, performance-oriented PA climate 
during this stage of life..$^{33}$ This may discourage youth who are primarily motivated to engage in nonorganized PA for non-achievement reasons, such as friendship or a positive sense of self. ${ }^{35}$

Adolescents may also face social pressure to refrain from 'childish' types of $\mathrm{PA},{ }^{34}$ which may dissuade participation in some forms of non-organized PA.

The stable trend in organized PA in the present study is also consistent with national cross-sectional statistics, in which the difference in organized MVPA between 9-11 and 12-14 years of age was not statistically significant. ${ }^{4}$ This trend may reflect the 'specialisation' in sport which tends to occur during adolescence. ${ }^{36}$ Adolescents who are not already engaging in organized PA in the transition to adolescence may lack the physical proficiency required to join, ${ }^{37,38}$ whereas those who have developed these skills may be more inclined to continue.

Active transport peaked at 13 years of age among both sexes in the present study, although the trend was statistically significant for boys only. This result was not evident in national cross-sectional data in Australia, ${ }^{4}$ although a statistically significant increase in active transport was evident among boys but not girls in an Australian longitudinal study ( $\mathrm{n}=201)$ between $10-12$ years and 13-15 years. ${ }^{39}$ Parents generally become more confident in their child's ability to travel independently as they age, particularly around 12 years of age. ${ }^{40}$ However, the transition from primary to high school may inhibit active transport participation due to greater travel distances to school and changes in peer group dynamics. ${ }^{39,41}$ There is also evidence that some forms of active transport (e.g. cycling) may become less fashionable or 'cool' in high school years, thus leading to a decline in participation. ${ }^{42}$

In the present study, active chores and work increased and then stabilized. This domain was not reported in national ABS data, ${ }^{4}$ although the present trend was consistent with studies included in a recent systematic review ${ }^{9,10}$ and a previous longitudinal study of household chores in general. ${ }^{43}$ Participation in active chores/work was not moderated by sex in the present study, which was also consistent with the previous longitudinal trend in general household chores. ${ }^{43}$. However there is evidence that sex differences in household work may intensify in later adolescence. ${ }^{44}$ 
LSAC is the only known public source of national longitudinal time-use data collected from

261 Australian children and adolescents. ${ }^{45}$ However, the use of this dataset in the present study has

262 incurred some limitations. Although other 24-hour TUD instruments have collected reliable ${ }^{46}$ and

$263 \operatorname{valid}^{47}$ data, there may be some variation between days of the week in the present study. This was

264 partially mitigated by controlling for school attendance on the day of TUD completion. Recall bias

265 may also be evident due to the self-report nature of the TUD. However, self-report methods are often

266 used to measure participation in domains of PA because this information cannot easily be obtained via

267 more objective methods such as accelerometry. ${ }^{48}$ There were also slight changes in the wording of

268 TUD activity codes between waves, although the PA domains generally harmonise well as a whole.

269 However, it is worth noting that organized PA may have been underestimated because school PE

270 lessons were not measured in these waves. LSAC is also a 'closed' longitudinal study, which means

271 that no participants have been recruited since baseline. Immigrants arriving in Australia after 2004 are

272 not included, which may affect the representativeness of the cohort indicated by the 'language spoken

273 at home' variable. ${ }^{20}$ In addition, interaction models did not control for multiple comparisons so the

274 results should be interpreted in this light. It is also worth noting that girls tend to enter puberty earlier

275 than boys ${ }^{49}$ and this may be a factor in girls' earlier decline in non-organized PA. ${ }^{50}$ Future studies

276 should therefore include pubertal status in longitudinal analyses. Finally, although the chosen

277 population weight was the best available option, it does not account for non-response beyond wave 4.

278 Despite these limitations, the present study contributes to a better understanding of longitudinal

279 changes in participation in domains of PA. The concurrent examination of multiple domains of PA

280 has identified non-organized PA as the domain most prone to decline during the transition from

281 childhood to adolescence in the present sample. The external validity of this trend in the Australian

282 context is supported by national cross-sectional statistics. ${ }^{4}$ This information may be useful in

283 designing more nuanced health promotion strategies targeting the decline in non-organized PA, ${ }^{51}$

284 particularly in Australia. For example, future interventions may seek to adapt aspects of Högman's

285 'organised spontaneous sport' approach, which provided a supervised location for youth to engage in

286 informal sports of their own choosing. ${ }^{52}$ This strategy may be expanded to allow youth to engage in a 
wider variety of physical activities that may not be categorized as 'sports', such as playground games or parkour. This approach would benefit from additional research to provide a more detailed understanding of specific types of non-organized PA that are prone to decline. ${ }^{8}$

The present study has also highlighted moderators of change in some domains of PA. This information may be used to target particular population segments at specific ages ${ }^{17}$ For example, nonorganized PA declined more steeply between 11 and 13 years among girls and those from a nonEnglish speaking background. Australian interventions seeking to promote non-organized PA during the transition to adolescence may consider targeting these population segments. This strategy may be enhanced by additional research to identify the broader determinants of non-organized PA in the transition from childhood to adolescence.

\section{Conclusion}

This study explored longitudinal trends in participation in domains of PA among Australian youth during the transition to adolescence. Non-organized PA was the most prone to decline during this transition, with the steepest declines occurring among girls and those from a non-English speaking background between 11 and 13 years of age. These results highlight potential opportunities to lessen the longitudinal decline in PA participation by targeting non-organized PA during the transition from childhood to adolescence. Future intervention strategies may be best targeted at girls or those from a non-English speaking background during the transition to adolescence.

Acknowledgements: Author 1 (BK) is a recipient of an Australian Government Research Training Program Scholarship. This paper uses unit record data from Growing Up in Australia, the Longitudinal Study of Australian Children. The study is conducted in partnership between the Department of Social Services (DSS), the Australian Institute of Family Studies (AIFS) and the Australian Bureau of Statistics (ABS). The findings and views reported in this paper are those of the authors and should not be attributed to DSS, AIFS or the ABS.

\section{Funding sources: nil}


313 1. Poitras VJ, Gray CE, Borghese MM, et al. Systematic review of the relationships between objectively measured physical activity and health indicators in school-aged children and youth. Appl Physiol Nutr Metab. 2016;41(6):S197-S239. doi: http://dx.doi.org/10.1139/apnm-2015-0663

2. World Health Organization. Global recommendations on physical activity for health. 2010; http://www.who.int/dietphysicalactivity/factsheet recommendations/en/. Accessed 8 June, 2017.

3. Hallal PC, Andersen LB, Bull FC, Guthold R, Haskell W, Ekelund U. Global physical activity levels: surveillance progress, pitfalls, and prospects. Lancet. 2012;380(9838):247257. doi: http://dx.doi.org/10.1016/S0140-6736(12)60646-1

4. Australian Bureau of Statistics. Australian Health Survey: Physical Activity, 2011-12 Australia, Table 2.1 Summary activity indicators by age then sex, children aged 5-17 years, cat. no. 4364.0.55.004.2013; https://www.abs.gov.au/ausstats/abs@.nsf/mf/4364.0.55.004. Accessed 27 March, 2017.

5. Dumith SC, Gigante DP, Domingues MR, Kohl HW. Physical activity change during adolescence: a systematic review and a pooled analysis. Int J Epidemiol. 2011;40(3):685-698. doi: http://dx.doi.org/10.1093/ije/dyq272

6. Telama R. Tracking of physical activity from childhood to adulthood: a review. Obes Facts. 2009;2(3):187-195. doi: https://doi.org/10.1159/000222244

7. World Health Organization. Global recommendations on physical activity for health. 2010; https://apps.who.int/iris/bitstream/handle/10665/44399/9789241599979_eng.pdf;jsessionid=6 C0980C710F6EC6A85A1969C8F276C77?sequence=1. Accessed 29 July, 2019.

8. Active Healthy Kids Australia. Physical literacy: do our kids have all the tools? The 2016 Active Healthy Kids Australia report card on physical activity for children and young people. 2016; http://www.activehealthykidsaustralia.com.au/siteassets/documents/ahka-2016summary_form-report-card.pdf. Accessed 27 June, 2017. 
9. Brooke HL, Corder K, Griffin SJ, van Sluijs EM. Physical activity maintenance in the transition to adolescence: a longitudinal study of the roles of sport and lifestyle activities in British youth. PLoS One. 2014;9(2):1-8. doi: http://dx.doi.org/10.1371/journal.pone.0089028

10. Lee PH. Association between adolescents' physical activity and sedentary behaviors with change in BMI and risk of type 2 diabetes. PLoS One. 2014;9(10):1-8. doi: http://dx.doi.org/10.1371/journal.pone.0110732

11. Hardy LL, King L, Espinel P, Cosgrove C, Bauman A. NSW Schools Physical Activity and Nutrition Survey (SPANS) 2010: full report. 2010; http://www.health.nsw.gov.au/heal/Pages/spans-2010-full-report.aspx. Accessed 28 September, 2017.

12. De Baere S, Seghers J, Philippaerts R, De Martelaer K, Lefevre J. Intensity-and domainspecific levels of physical activity and sedentary behavior in 10-to 14-year-old children. $J$ Phys Act Health. 2015;12(12):1543-1550. doi: http://dx.doi.org/10.1123/jpah.2014-0416

13. Kemp BJ, Cliff DP, Chong KH, Parrish AM. Longitudinal changes in domains of physical activity during childhood and adolescence: a systematic review. J Sci Med Sport. 2019;22(6):695-701. doi: https://doi.org/10.1016/j.jsams.2018.12.012

14. Eime RM, Harvey JT, Sawyer NA, Craike MJ, Symons CM, Payne WR. Changes in sport and physical activity participation for adolescent females: a longitudinal study. BMC Public Health. 2016;16(1):533-539. doi: http://dx.doi.org/10.1186/s12889-016-3203-x

15. Rauner A, Jekauc D, Mess F, Schmidt S, Woll A. Tracking physical activity in different settings from late childhood to early adulthood in Germany: the MoMo longitudinal study. BMC Public Health. 2015;15(1):391-401. doi: http://dx.doi.org/10.1186/s12889-015-1731-4

16. van Mechelen W, Twisk JW, Post GB, Snel J, Kemper HCG. Physical activity of young people: the Amsterdam Longitudinal Growth and Health Study. Med Sci Sports Exerc. 2000;32(9):1610-1616

17. National Social Marketing Centre. Big pocket guide: social marketing. 2011; www.thensmc.com/sites/default/files/Big_pocket_guide_2011.pdf. Accessed 30 January, 2018. 
18. Australian Institute of Health and Welfare. Social determinants overview. 2018; https://www.aihw.gov.au/reports-data/behaviours-risk-factors/social-determinants/overview. Accessed 8 July, 2019.

19. Australian Institute of Health and Welfare. Mortality inequalities in Australia, 2009-2011. 2014; https://www.aihw.gov.au/reports/social-determinants/mortality-inequalities-inaustralia-2009-11/contents/table-of-contents.

20. Australian Institute of Family Studies. The Longitudinal Study of Australian Children: an Australian Government initiative (data user guide). 2015; http://www.growingupinaustralia.gov.au/data/docs/userguide.pdf. Accessed 2 May, 2017.

21. Australian Institute of Family Studies. Data management issues, LSAC Discussion Paper 3. 2004; https://growingupinaustralia.gov.au/sites/default/files/lsacdiscussionpaper3.pdf. Accessed 2 May, 2017.

22. Corey J, Gallagher J, Davis E, Marquardt M. The times of their lives: collecting time use data from children in the Longitudinal Study of Australian Children (LSAC), LSAC Technical Paper 13. 2014; https://data.growingupinaustralia.gov.au/pubs/technical/tp13.pdf. Accessed 1 May, 2017.

23. Butte NF, Watson KB, Ridley K, et al. A youth compendium of physical activities: activity codes and metabolic intensities. Med Sci Sports Exerc. 2018;50(2):246. doi: https://doi.org/10.1249/MSS.0000000000001430

24. World Health Organization. What is moderate-intensity and vigorous-intensity physical activity? 2018; http://www.who.int/dietphysicalactivity/physical_activity_intensity/en/. Accessed 22 June, 2018.

25. Ridley K, Ainsworth BE, Olds TS. Development of a compendium of energy expenditures for youth. Int J Behav Nutr Phys Act. 2008;5(1):45. doi: https://doi.org/10.1186/1479-5868-5-45

26. Ainsworth BE, Haskell WL, Whitt MC, et al. Compendium of physical activities: an update of activity codes and MET intensities. Med Sci Sports Exerc. 2000;32(9):S498-S504

27. Blakemore T, Strazdins L, Gibbings J. Measuring family socioeconomic position. Aust Soc Policy. 2009;8:121-168 
28. Australian Bureau of Statistics. Remoteness structure. 2018; http://www.abs.gov.au/websitedbs/D3310114.nsf/home/remoteness+structure. Accessed 28 June, 2018.

29. Rabe-Hesketh S, Skrondal A. Multilevel and Longitudinal Modeling Using Stata. College Station, TX: Stata Press; 2008.

30. Australian Bureau of Statistics. 2016 Census Quickstats: Australia. 2018; http://www.censusdata.abs.gov.au/census services/getproduct/census/2016/quickstat/036?ope ndocument. Accessed 28 June, 2018.

31. Cumming SP, Sherar LB, Pindus DM, Coelho-e-Silva MJ, Malina RM, Jardine PR. A biocultural model of maturity-associated variance in adolescent physical activity. Int Rev Sport Exerc Psychol. 2012;5(1):23-43. doi: https://doi.org/10.1080/1750984X.2011.630481

32. Allison KR, Dwyer JJ, Goldenberg E, Fein A, Yoshida KK, Boutilier M. Male adolescents' reasons for participating in physical activity, barriers to participation, and suggestions for increasing participation. Adolescence. 2005;40(157)

33. Martins J, Marques A, Sarmento H, Carreiro da Costa F. Adolescents' perspectives on the barriers and facilitators of physical activity: a systematic review of qualitative studies. Health Educ Res. 2015;30(5):742-755. doi: https://doi.org/10.1093/her/cyv042

34. Devís-Devís J, Beltrán-Carrillo VJ, Peiró-Velert C. Exploring socio-ecological factors influencing active and inactive Spanish students in years 12 and 13. Sport Educ Soc. 2015;20(3):361-380. doi: https://doi.org/10.1080/13573322.2012.754753

35. Scanlan TK, Lewthwaite R. Social psychological aspects of competition for male youth sport participants: IV. Predictors of enjoyment. J Sport Psychol. 1986;8(1):25-35. doi: https://doi.org/10.1123/jsp.8.1.25

36. MacPhail A, Kirk D. Young people's socialisation into sport: experiencing the specialising phase. Leis Stud. 2006;25(1):57-74. doi: https://doi.org/10.1080/02614360500116290

37. Brooks F, Magnusson J. Physical activity as leisure: the meaning of physical activity for the health and well-being of adolescent women. Health Care Women Int. 2007;28(1):69-87. doi: https://doi.org/10.1080/07399330601003499 
38. Thompson AM, Humbert ML, Mirwald RL. A longitudinal study of the impact of childhood and adolescent physical activity experiences on adult physical activity perceptions and behaviors. Qual Health Res. 2003;13(3):358-377. doi: https://doi.org/10.1177/1049732302250332

39. Carver A, Timperio AF, Hesketh KD, Ridgers ND, Salmon JL, Crawford DA. How is active transport associated with children's and adolescents' physical activity over time? Int J Behav Nutr Phys Act. 2011;8(126):1-6. doi: https://doi.org/10.1186/1479-5868-8-126

40. $\quad$ Faulkner GE, Richichi V, Buliung RN, Fusco C, Moola F. What's "quickest and easiest?": parental decision making about school trip mode. Int J Behav Nutr Phys Act. 2010;7(1):62. doi: https://doi.org/10.1186/1479-5868-7-62

41. Sirard JR, Slater ME. Walking and bicycling to school: a review. Am J Lifestyle Med. 2008;2(5):372-396. doi: https://doi.org/10.1177\%2F1559827608320127

42. Underwood SK, Handy SL, Paterniti DA, Lee AE. Why do teens abandon bicycling? A retrospective look at attitudes and behaviors. J Transp Health. 2014;1(1):17-24. doi: https://doi.org/10.1016/j.jth.2013.12.002

43. Lam CB, Greene KM, McHale SM. Housework time from middle childhood through adolescence: links to parental work hours and youth adjustment. Dev Psychol. 2016;52(12):2071. doi: https://doi.org/10.1037/dev0000223

44. Hilbrecht M, Zuzanek J, Mannell RC. Time use, time pressure and gendered behavior in early and late adolescence. Sex Roles. 2008;58(5-6):342-357. doi: https://doi.org/10.1007/s11199$\underline{007-9347-5}$

45. Centre for Time Use Research. Access time use data. n.d.; https://www.timeuse.org/information/access-data. Accessed 25 May, 2018.

46. Ridley K, Olds TS, Hill A. The Multimedia Activity Recall for Children and Adolescents (MARCA): development and evaluation. Int J Behav Nutr Phys Act. 2006;3(1):10. doi: https://dx.doi.org/10.1186\%2F1479-5868-3-10 
47. Gershuny J, Harms T, Doherty A, et al. Testing self-report time-use diaries against objective instruments in real time. 2017; https://www.timeuse.org/sites/default/files/201710/CTUR\%20WP\%2010\%202017.pdf. Accessed 29 January, 2018.

48. Warren JM, Ekelund U, Besson H, Mezzani A, Geladas N, Vanhees L. Assessment of physical activity - a review of methodologies with reference to epidemiological research: a report of the exercise physiology section of the European Association of Cardiovascular Prevention and Rehabilitation. Eur J Cardiovasc Prev Rehabil. 2010;17(2):127-139. doi: http://dx.doi.org/10.1097/HJR.0b013e32832ed875

49. Petersen AC, Crockett L, Richards M, Boxer A. A self-report measure of pubertal status: reliability, validity, and initial norms. $J$ Youth Adolesc. 1988;17(2):117-133. doi: https://doi.org/10.1007/BF01537962

50. Drenowatz C, Eisenmann JC, Pfeiffer KA, Wickel EE, Gentile D, Walsh D. Maturity-related differences in physical activity among 10-to 12-year-old girls. Am J Hum Biol. 2010;22(1):18-22. doi: https://doi.org/10.1002/ajhb.20905

51. Sallis JF. Age-related decline in physical activity: a synthesis of human and animal studies. Med Sci Sports Exerc. 2000;32(9):1598-1600

52. Högman J, Augustsson C. To play or not to play, that's the question-young people's experiences of organized spontaneous sport. Sport in Society. 2017;20(9):1134-1149. doi: https://doi.org/10.1080/17430437.2016.1269080 
Table 1 Characteristics of the analytic sample ${ }^{\text {a }}$, unweighted LSAC data

\begin{tabular}{|c|c|c|c|c|c|c|}
\hline & \multicolumn{2}{|c|}{ Wave $4(n=3994)$} & \multicolumn{2}{|c|}{ Wave $5(n=3573)$} & \multicolumn{2}{|c|}{ Wave $6(n=3014)$} \\
\hline & Boys & Girls & Boys & Girls & Boys & Girls \\
\hline Sex, n (\%) & $2035(51.0 \%)$ & $1959(49.0 \%)$ & $1807(50.6 \%)$ & $1766(49.4 \%)$ & $1515(50.3 \%)$ & $1499(49.7 \%)$ \\
\hline Age, mean (SD) & $10.9(0.3)$ & $10.9(0.3)$ & $12.9(0.3)$ & $12.9(0.3)$ & $14.9(0.3)$ & $14.9(0.3)$ \\
\hline $\begin{array}{l}\text { Speaks language other than English at home, } \\
(\%)^{\mathrm{b}}\end{array}$ & $167(8.4 \%)$ & $146(7.7 \%)$ & $129(7.2 \%)$ & $127(7.2 \%)$ & $97(6.6 \%)$ & $116(7.9 \%)$ \\
\hline Aboriginal or Torres Strait Islander, $\mathrm{n}(\%)^{\mathrm{b}}$ & $52(2.6 \%)$ & $58(3.0 \%)$ & $35(1.9 \%)$ & $43(2.4 \%)$ & $28(1.9 \%)$ & $30(2.0 \%)$ \\
\hline Lives in regional or remote area, $\mathrm{n}(\%)^{\mathrm{b}}$ & $711(35.1 \%)$ & $695(35.6 \%)$ & $644(35.6 \%)$ & $645(36.5 \%)$ & $520(34.3 \%)$ & $543(36.2 \%)$ \\
\hline Attended school on day of TUD, $\mathrm{n}(\%)$ & $1060(52.1 \%)$ & $1038(53.0 \%)$ & $936(51.8 \%)$ & $1010(57.2 \%)$ & $695(45.9 \%)$ & $712(47.5 \%)$ \\
\hline \multicolumn{7}{|l|}{ Season of measurement, $\mathrm{n}(\%)$} \\
\hline Summer & $8(0.4 \%)$ & $9(0.5 \%)$ & $59(3.3 \%)$ & $51(2.9 \%)$ & $42(2.8 \%)$ & $53(3.5 \%)$ \\
\hline Autumn & $510(25.1 \%)$ & $542(27.7 \%)$ & $330(18.3 \%)$ & $329(18.6 \%)$ & $353(23.3 \%)$ & $370(24.7 \%)$ \\
\hline Winter & $1056(51.9 \%)$ & $992(50.6 \%)$ & $808(44.7 \%)$ & 775 (43.9\%) & $609(40.2 \%)$ & $585(39.0 \%)$ \\
\hline Spring & $461(22.7 \%)$ & $416(21.2 \%)$ & $610(33.8 \%)$ & $611(34.6 \%)$ & $511(33.7 \%)$ & $491(32.8 \%)$ \\
\hline
\end{tabular}

$470 \quad$ LSAC $=$ Longitudinal Study of Australian Children; $n=$ number of participants; $\%=$ proportion of analytic sample; $\mathrm{SD}=$ standard deviation; $\mathrm{TUD}=$ time use diary

471 a. The sample shown here was included in main models (PA domains by wave) which required valid data for PA domains on at least one occasion and a valid data weight 
Table 2 Participation in domains of PA (minutes/day) by wave, weighted LSAC data

\begin{tabular}{|c|c|c|c|c|c|c|}
\hline & & Organized PA & Non-organized PA & Active transport & Active work/ chores & Overall PA \\
\hline \multicolumn{7}{|c|}{ PA domains, minutes/day } \\
\hline Wave $4(n=3994)$ & Mean (SD) & $23.84(51.59)$ & $72.54(83.54)$ & $12.49(27.43)$ & $11.89(30.25)$ & $120.76(100.37)$ \\
\hline Wave $5(n=3573)$ & Mean (SD) & $22.47(54.45)$ & $35.58(66.70)$ & $16.08(34.64)$ & $15.74(39.45)$ & $89.86(95.85)$ \\
\hline Wave $6(n=3014)$ & Mean (SD) & $22.94(54.86)$ & $24.78(57.87)$ & $12.83(28.74)$ & $15.40(41.38)$ & $75.95(91.48)$ \\
\hline \multicolumn{7}{|c|}{ Unadjusted models a } \\
\hline \multirow[t]{3}{*}{ Fixed effect - wave } & $\beta(95 \% \mathrm{CI})$ & $-9.83(-31.11,11.45)$ & $-155.21(-183.75,-$ & 34.33 (20.29, & $22.86(5.85,39.87)$ & $-107.67(-146.82,-$ \\
\hline & & & 126.66) & 48.36) & & 68.53) \\
\hline & $\mathrm{p}$ value & 0.365 & $<0.001$ & $<0.001$ & 0.008 & $<0.001$ \\
\hline Fixed effect - & $\beta(95 \% \mathrm{CI})$ & $0.92(-1.22,3.06)$ & $13.15(10.32,15.97)$ & $-3.41(-4.82,-2.00)$ & $-2.11(-3.83,-0.39)$ & $8.53(4.62,12.44)$ \\
\hline wave $^{2}$ & $\mathrm{p}$ value & 0.398 & $<0.001$ & $<0.001$ & 0.016 & $<0.001$ \\
\hline \multicolumn{7}{|l|}{ Adjusted models ab } \\
\hline \multirow[t]{4}{*}{ Fixed effect - wave } & $\beta(95 \% \mathrm{CI})$ & $-6.37(-28.35,15.60)$ & $-151.60(-179.14,-$ & $29.73(15.68$ & $27.65(11.12,44.18)$ & $-100.30(-138.84,-$ \\
\hline & & & 124.07) & 43.78) & & 61.77) \\
\hline & $\mathrm{p}$ value & 0.570 & $<0.001$ & $<0.001$ & 0.001 & $<0.001$ \\
\hline & $\beta(95 \% \mathrm{CI})$ & $0.64(-1.57,2.85)$ & $12.66(9.92,15.39)$ & $-2.96(-4.37,-1.55)$ & $-2.66(-4.32,-0.99)$ & $7.65(3.80,11.51)$ \\
\hline
\end{tabular}


Fixed effect -

0.569

$<0.001$

$<0.001$

0.002

$<\mathbf{0 . 0 0 1}$

Post hoc models - differences between waves ${ }^{a b}$

$\mathrm{W} 4 \rightarrow \mathrm{W} 5$

$\beta(95 \% \mathrm{CI}) \quad-0.26(-2.72,2.20)$

$-37.58(-40.98,-34.18) \quad 3.08(1.57,4.60)$

$3.73(2.01,5.45)$

$-31.00(-35.47,-26.54)$

W5 $\rightarrow \mathrm{W} 6$

$\mathrm{p}$ value

0.836

$<0.001$

$<0.001$

$<0.001$

$<0.001$

$\mathrm{W} 5 \rightarrow \mathrm{W} 6$

$\beta(95 \% \mathrm{CI}) \quad 0.54(-2.14,3.21)$

$-12.12(-15.24,-8.99)$

$-2.66(-4.35,-0.97)$

$-1.74(-3.77,0.30)$

$-15.96(-20.57,-11.34)$

$\mathrm{p}$ value

0.695

$<0.001$

0.002

0.094

$<0.001$

$\mathrm{W} 4 \rightarrow \mathrm{W} 6$

$\beta(95 \% \mathrm{CI}) \quad-0.19(-2.72,2.34)$

$-49.99(-53.65,-46.32)$

$0.31(-1.17,1.79)$

$2.32(0.57,4.07)$

$-47.45(-52.31,-42.58)$

$\mathrm{p}$ value

0.884

$<0.001$

0.680

0.009

$<0.001$

$\mathrm{PA}=$ physical activity LSAC $=$ Longitudinal Study of Australian Children; $\mathrm{SD}=$ standard deviation; $\beta=$ model coefficient $\mathrm{CI}=$ confidence interval; $\mathrm{W}=$ wave

a. Multilevel mixed models $(\mathrm{n}=4108)$

b. Adjusted for season and school attendance on the day of TUD completion

Bold text indicates statistical significance $(\mathrm{p}<0.05)$ 
475 Table 3 Participation in domains of PA (minutes/day), statistically significant effect moderators of 476 wave, weighted LSAC data ${ }^{\text {a }}$

\begin{tabular}{|c|c|c|c|c|}
\hline Moderator & & Non-organized PA & Active transport & Overall PA \\
\hline \multicolumn{5}{|c|}{ Interactions with wave - adjusted models ${ }^{b}$} \\
\hline Sex & $\beta(95 \% \mathrm{CI})$ & $-53.39(-108.75,1.96)$ & $-45.20(-72.91,-$ & $-118.12(-194.86,-$ \\
\hline \multirow[t]{2}{*}{$(\text { girls })^{\mathrm{c}}$} & & & 17.50) & 41.39) \\
\hline & $\mathrm{p}$ value & 0.059 & 0.001 & 0.003 \\
\hline LOTE & $\beta(95 \% \mathrm{CI})$ & $-85.51(-171.26,0.24)$ & $-33.76(-78.13$ & $-175.43(-303.36,-$ \\
\hline (languages & & & 10.62) & 47.50) \\
\hline other than & & & & \\
\hline English) ${ }^{\mathrm{d}}$ & $\mathrm{p}$ value & 0.051 & 0.136 & 0.007 \\
\hline
\end{tabular}

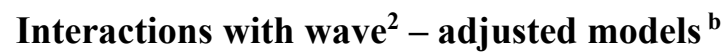

$\begin{array}{lcccc}\text { Sex } & \beta(95 \% \text { CI }) & 5.55(0.07,11.03) & 4.40(1.61,7.18) & 11.74(4.07,19.41) \\ (\text { girls })^{\text {c }} & \text { p value } & 0.047 & 0.002 & 0.003\end{array}$

LOTE $\quad \beta(95 \% \mathrm{CI}) \quad \mathbf{8 . 5 5}(\mathbf{0 . 1 2}, \mathbf{1 6 . 9 8}) \quad 3.46(-0.96,7.87) \quad \mathbf{1 7 . 4 7}(\mathbf{4 . 7 9 , 3 0 . 1 6 )}$

(languages



English) ${ }^{\mathrm{d}}$

Post-hoc models - differences between waves, by sex

Boys

\begin{tabular}{|c|c|c|c|c|}
\hline $\mathrm{W} 4 \rightarrow \mathrm{W} 5$ & $\begin{array}{l}\beta(95 \% \\
\mathrm{CI})\end{array}$ & $-36.16(-41.40,-30.92)$ & $5.67(3.48,7.86)$ & $\begin{array}{c}-25.01(-31.56,- \\
18.47)\end{array}$ \\
\hline & $p$ value & $<0.001$ & $<0.001$ & $<0.001$ \\
\hline
\end{tabular}




\begin{tabular}{|c|c|c|c|c|}
\hline \multirow[t]{2}{*}{$\mathrm{W} 5 \rightarrow \mathrm{W} 6$} & $\begin{array}{l}\beta(95 \% \\
\mathrm{CI})\end{array}$ & $-16.15(-21.21,-11.08)$ & $-4.32(-6.74,-1.90)$ & $\begin{array}{c}-21.55(-28.37 \\
14.74)\end{array}$ \\
\hline & $\mathrm{p}$ value & $<0.001$ & $<0.001$ & $<0.001$ \\
\hline \multirow[t]{2}{*}{$\mathrm{W} 4 \rightarrow \mathrm{W} 6$} & $\begin{array}{l}\beta(95 \% \\
\mathrm{CI})\end{array}$ & $-52.51(-58.02,-47.00)$ & $1.62(-0.37,3.60)$ & $\begin{array}{c}-46.86(-53.95 \\
39.76)\end{array}$ \\
\hline & $p$ value & $<0.001$ & 0.110 & $<0.001$ \\
\hline
\end{tabular}

\section{Girls}

\begin{tabular}{|c|c|c|c|c|}
\hline \multirow[t]{2}{*}{$\mathrm{W} 4 \rightarrow \mathrm{W} 5$} & $\begin{array}{l}\beta(95 \% \\
\text { CI })\end{array}$ & $-39.01(-43.24,-34.77)$ & $0.37(-1.70,2.45)$ & $\begin{array}{c}-37.14(-43.16,- \\
31.13)\end{array}$ \\
\hline & $\mathrm{p}$ value & $<0.001$ & 0.725 & $<0.001$ \\
\hline \multirow[t]{3}{*}{$\mathrm{W} 5 \rightarrow \mathrm{W} 6$} & $\beta(95 \%$ & & $087(210145)$ & $004(1500260)$ \\
\hline & CI) & & 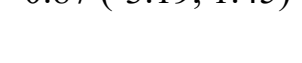 & ) \\
\hline & $\mathrm{p}$ value & $<0.001$ & 0.462 & 0.002 \\
\hline \multirow[t]{3}{*}{$\mathrm{W} 4 \rightarrow \mathrm{W} 6$} & $\beta(95 \%$ & & & $-47.84(-54.46,-$ \\
\hline & $\mathrm{CI})$ & $-47.12(-51.87,-42.37)$ & $-1.00(-3.19,1.19)$ & 41.22) \\
\hline & $p$ value & $<0.001$ & 0.371 & $<0.001$ \\
\hline
\end{tabular}

Post-hoc models - differences between waves, by LOTE

English spoken at home

\begin{tabular}{|c|c|c|c|c|}
\hline $\mathrm{W} 4 \rightarrow \mathrm{W} 5$ & $\begin{array}{l}\beta(95 \% \\
\text { CI })\end{array}$ & $-37.60(-41.24,-33.96)$ & $1.55(-3.06,6.15)$ & $\begin{array}{c}-31.10(-35.84 \\
26.35)\end{array}$ \\
\hline & $\mathrm{p}$ value & $<0.001$ & 0.511 & $<0.001$ \\
\hline $\mathrm{W} 5 \rightarrow \mathrm{W} 6$ & $\begin{array}{l}\beta(95 \% \\
\mathrm{CI})\end{array}$ & $-12.91(-16.24,-9.57)$ & $0.26(-4.45,4.98)$ & $\begin{array}{c}-17.37(-22.31,- \\
12.42)\end{array}$ \\
\hline & $\mathrm{p}$ value & $<0.001$ & 0.913 & $<0.001$ \\
\hline $\mathrm{W} 4 \rightarrow \mathrm{W} 6$ & $\begin{array}{l}\beta(95 \% \\
\mathrm{CI})\end{array}$ & $-50.59(-54.49,-46.69)$ & $1.44(-3.26,6.15)$ & $\begin{array}{c}-49.10(-54.20,- \\
44.00)\end{array}$ \\
\hline
\end{tabular}


$\begin{array}{llll}\text { p value } & <\mathbf{0 . 0 0 1} & 0.548 & <\mathbf{0 . 0 0 1}\end{array}$

Other languages spoken at home

$\mathrm{W} 4 \rightarrow \mathrm{W} 5 \quad \beta(95 \%$

CI)

$\mathrm{p}$ value

$\mathrm{W} 5 \rightarrow \mathrm{W} 6 \quad \beta(95 \%$

CI)

$\mathrm{p}$ value

$\mathrm{W} 4 \rightarrow \mathrm{W} 6 \quad \beta(95 \%$

CI)

$\mathrm{p}$ value

$$
-52.04(-64.34,-39.74)
$$

$-46.11(-56.90,-35.33)$

$<0.001$

$-4.28(-13.03,4.48)$

0.338

$<0.001$
$0.15(-1.72,1.43)$

$3.10(1.48,4.73)$

$<0.001$

$\mathbf{- 3 . 1 1}(-\mathbf{4 . 9 3}, \mathbf{- 1 . 2 8}) \quad-1.74(-15.74,12.26)$

0.001

0.808

$-51.39(-68.82,-$ 33.95)

$<0.001$
477

478

479

480

481

482

483

484

485

486

$\mathrm{PA}=$ physical activity LSAC $=$ Longitudinal Study of Australian Children; $\beta=$ model coefficient; $\mathrm{CI}=$ confidence intervals; LOTE = whether languages other than English spoken at home; W=wave

a. Effect modifiers that were not statistically significant are listed in Supplementary File 2 (including effects tested for other domains of PA)

b. Multilevel mixed models: PA domains by sex $(n=4108)$ and LOTE $(n=4085)$, adjusted for season and school attendance on the day of TUD completion

c. Reference category: boys

d. Reference category: English spoken at home 
Figure 1 Mean minutes/day of participation in overall PA and domains of PA, by age of participants, weighted LSAC data

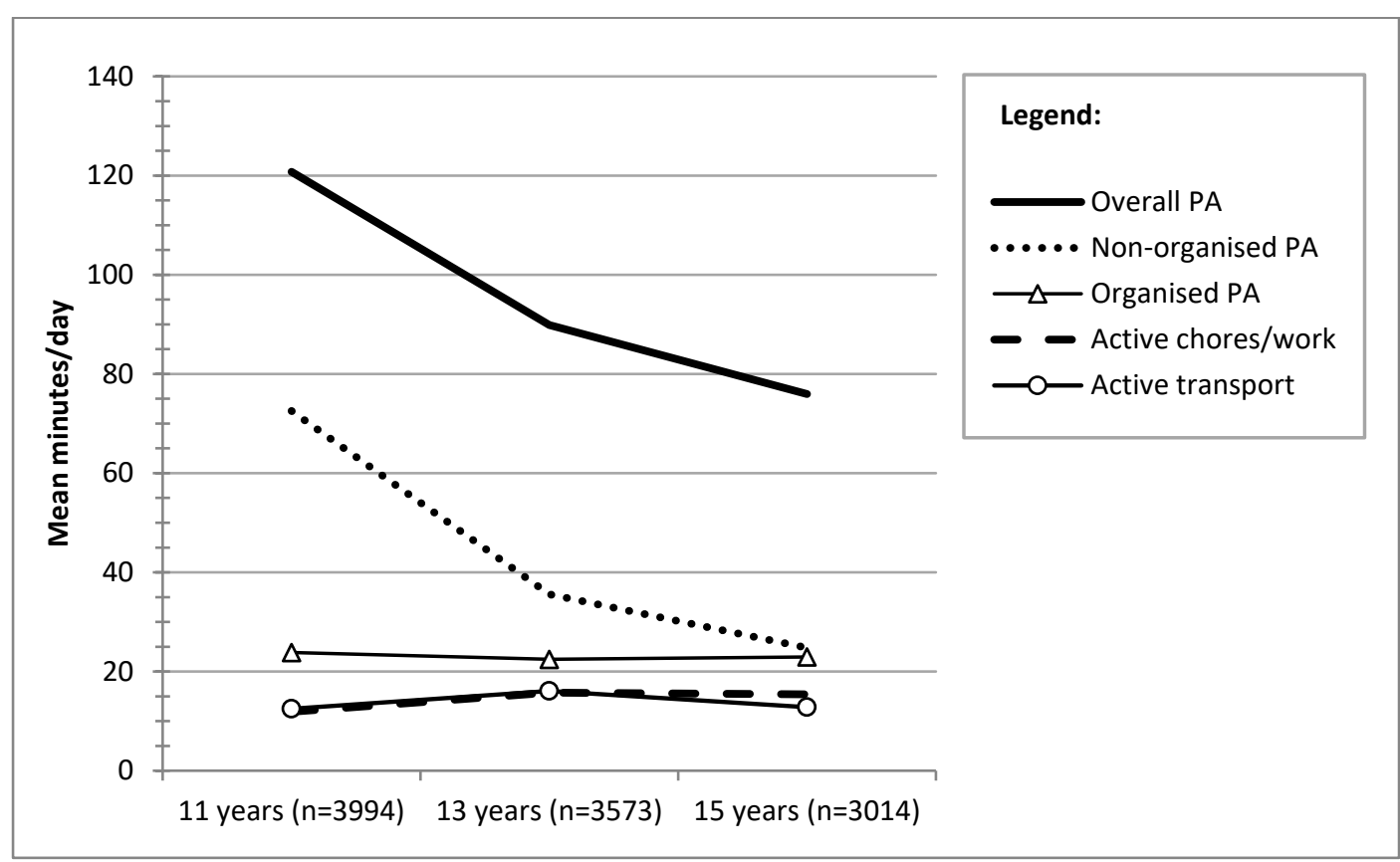

PA $=$ physical activity; LSAC $=$ Longitudinal Study of Australian Children; $n=$ number of participants 